\title{
Control of aquatic leeches (Lymnatis nilotica) us- ing Phytolacca dodecandra (Endod) in Sodo District, Gurage Zone, Southern Nations, Nationalities and Peoples Region, Ethiopia
}

\author{
${ }^{1 *}$ Tadesse Eguale, ${ }^{2}$ Getnet Abie, ${ }^{2}$ Mesfin Sahile, ${ }^{2}$ Daniel Gizaw \\ ${ }^{1}$ Aklilu Lemma Institute of Pathobiology, College of Health Sciences, \\ Addis Ababa University, P.O. Box 1176, Addis Ababa, Ethiopia \\ ${ }^{2}$ National Animal Health Diagnostic and Investigation Center, P.O. Box 04, Sebeta, Ethiopia \\ *Corresponding author: tadesseeguale@yahoo.com
}

\section{Abstract}

Infestation of cattle by leeches and occasional attack of humans is becoming serious problem in some parts of the country. The objective of this study is to investigate the prevalence of leech in selected streams in Sodo district, Southern Nations, Nationalities and Peoples Region and to evaluate the efficacy of endod on leech in field condition and its impact on other non-target aquatic fauna following the request of the district craving for intervention. Estimation of prevalence of leech was assessed before application; $24 \mathrm{hrs}, 10$ days and 30 days post application of endod based on the number of leeches collected per person per 5 minutes. Findings from interview of the local communities revealed that $95 \%$ of the respondents rated leech as the major animal health problem in the district and $65 \%$ of them have seen human infested by leech at least once in their life. The mean leech count per person per 5 minutes before application of endod ranged from 16.8-38 in different streams. Stock solution of endod berries suspended in water for 16 hrs was continuously applied to various streams so as to maintain concentration of $20 \mathrm{~g} /$ $\mathrm{m}^{3}$ of water for $6 \mathrm{hrs}$. Application of endod caused mortality of most of the leech population resulting in $97-100 \%$ reduction which persisted for minimum of 30 days post application in most of the streams. Most of the local communities witnessed that endod rendered the treated water bodies free of leech for 2-3 months. It has also caused mortality of tadpoles, frogs and round worms found in streams while it doesn't cause any visible toxicity to different water insects. Moreover, no livestock toxicity due to endod was recorded post application. In conclusion, endod can be used to control leech without causing serious toxicity to most of the aquatic fauna, human and livestock with continuous application for 6 hrs at concentration of 20 $\mathrm{g} / \mathrm{m}^{3}$. However, care should be taken in using appropriate concentration and it should not be used in water bodies that contain fish because it is toxic to fish at the dose required to control leeches.

Keywords: Aquatic Leech/Lymnatis nilotica; Cattle; Phytolacca dodecandra/ Endod; Stream; Sodo district 


\section{Introduction}

Leeches are segmented worms under Phylum Annelida and Class Hirudinae. The distinctive properties of leeches from other Annelids are the presence of anterior and posterior suckers, constant number of body segments and body cavity largely filled with muscles and connective tissue. Leeches that attach to animals and humans belong to the family Blunered (Schmidt, 1994). These leeches are commonly found in lakes, ponds, springs, small streams and pools of water (Soulsby, 1986). They have strong muscular suckers, the anterior one surrounding the mouth, which contains saw-like teeth is used to pierce the skin of the host (Edward, 1998). Leeches feed on blood of various animals to which they attach themselves and drop off after having engorged (Soulsby, 1986). The parasites get into the mouth when the animals drink infested water and attaches to oro-pharingeal and laryngeal mucus membrane by means of powerful terminal sucker. Using this sucker, they pierce the epidermis and suck blood (Lapage, 1962). Their presence in these locations may cause severe bouts of coughing and chocking during which blood is ejected by victim (George et al., 1990; Edward, 1998).

A salivary enzyme hirudin secreted by the parasite acts as anticoagulant and assures a copious flow of blood, which sometimes cause anemia. Bleeding may continue for some time after the leech has dropped off. Blood or bloody froth may often be seen exuding from the mouth or nostrils of the animals. There is dyspnea and in severe cases the neck is extended and the mouth is held open. Edematous swelling may be seen in the parotid and intermandiblar regions. Death may be caused by asphyxia and it may occur suddenly as a result of edema of the glottis. They may also cause inflammation and trauma of pharyngeal area leading to secondary microbial complication and prohibition of swallowing (Soulsby, 1986).

Although detailed impact of the leech on livestock has not yet been studied in Ethiopia, several externship students of Faculty of Veterinary Medicine, Debre Zeit, have reported it as one of the animal health problem in rural areas. In some highland areas where small streams and ponds are used for watering of livestock, it is not uncommon to find cattle that suffer from the effect of this parasite. A pharyngeal leech infestation of cattle is very common especially during the dry season (Aklilu Lemma, 1984). It was reported to be one of the priority animal health problems in Amhara region where more than two million cattle are at risk (Thomas Cherinet, 2000). 
The possible options to alleviate the problem of leech infestation are either treating infested animals by chemicals or manual removal of the parasites or protecting water bodies free of leeches by application of hirudincidal chemicals. Chemotherapy by chemicals like chloroform water gives successful results. But it is irritant to the mucus membrane of the animal and there is difficulty in application (Soulsby, 1986). Moreover, the presence of leech in the oropharyngial region of the infected animal is detected after it has caused considerable loss of blood. Its expensive cost and uneasy accessibility are also other problem of using chemicals. Manual removal of the parasite is damaging to the tissue of the host. Therefore, treating water bodies seems more rational than treating infested animals. Application of commercial chemicals like copper sulphate, Ntrityl-morpholine and niclosamide to contaminated water is possible but these chemicals are expensive and they are toxic to other non-target organisms (Aklilu Lemma, 1984)

Traditionally, farmers drench some medicinal plants like tobacco and endod, prolong the watering period for 2 to 3 days to get rid of this parasite or remove manually (Personal observation). Although such traditional methods seem to produce encouraging results, studies should be conducted to assess their merits and de-merits. Therefore, it is worthy to investigate traditional herbs, which are effective, economical, and easy to use on mass basis. The preliminary laboratory trial of the berries of endod (Phytolacca dodecandra), showed promising result. Aklilu Lemma (1970) reported 100\% mortality of leeches at a concentration of 4 parts per million (ppm). Thomas Cherinet, (2000) reported the minimum concentration of endod required to achieve $100 \%$ mortality to be $100 \mathrm{ppm}$. Getachew Tilahun et al (2003) reported that the efficacy of endod varies based on the type of water medium in which endod is dissolved, i.e. highest in distilled water, medium in tape water and lowest in lake water.

Field trial on the control of leech using endod berries by Ministry of Agriculture and Ethio-Agri-SEFT at North Showa of Oromia Region and Gonder area, in Amhara Region showed promising results (Aweke Tsegaw, 2006; Mulualem Tarekegne, 2006). However, these works were conducted without initial assessment of the distribution of leech in water bodies. Without assessing the level of leech in water bodies before intervention, it is difficult to quantify the level by which the problem caused by leech is reduced. Moreover, the effect of endod on other aquatic fauna should also be investigated before wide scale application of endod on water bodies for leech control. 
National Animal Health Diagnostic and Investigation Center was assigned by Ministry of Agriculture and Rural Development to investigate the impact of leech on animal health in Sodo district, Gurage Zone of Southern Nations, Nationalities and Peoples Region (SNNPR), and to look for a control method following the enquiry of the district as a serious health problem. Therefore, the current study reports the works done to investigate the prevalence of leech in selected streams of Sodo district, and to evaluate field efficacy of endod on leech and its impact on other non-target aquatic fauna.

\section{Materials and methods}

\section{Study area}

Sodo district is located in Gurage Zone, SNNPR, about $100 \mathrm{Km}$ south west of Addis Ababa. The district is generally characterized by highlands and lowlands. Specific study site is along different streams near Amawute and Tiya town west of Tiya Tekil Dingay. The average altitude of the study area is 2550 $\mathrm{m}$ above sea level. The streams were located in 4 peasant associations (PAs). Sodo district contains several small streams whose water flow rate is reduced during the dry season of the year. As there is little tap water supply in the area, most of the people and livestock depend on these streams as a source of water supply.

Interview of livestock owners and local community

This study was conducted from November - March, 2009 during which livestock owners and other people of the local communities were interviewed on the impact of leech on animal health in their communities. Interview was made on the impact of leech in the area on animal health and humans before intervention and on the significance of endod application after intervention a month and 3 months later. Streams and specific sites along the streams for application of endod were also identified by the local people.

Preparation and application of endod

Powder of unripe berries of endod type 44 was purchased from Ethio AgriSEFT. Preparation and application of endod was based on the procedure described earlier (MOA, 2006). Briefly, the amount of endod required to treat the water bodies was calculated based on the volume of water flow which was estimated by multiplying the mean depth, width and speed of water flow per second. Speed of water flow was estimated by measuring the time required for small piece of paper to travel $4 \mathrm{~m}$ down the stream. All measurements were 
repeated at least 4 times at different places along the streams and the mean result was taken for calculation.

Volume of water flow $\left(\mathrm{m}^{3} / \mathrm{s}\right)=$ depth $(\mathrm{m}) \mathrm{X}$ width $(\mathrm{m}) \mathrm{X}$ speed $(\mathrm{m} / \mathrm{s})$

Amount of endod used per each stream $(\mathrm{Kg})=$ [volume of water flow $\left(\mathrm{m}^{3} / \mathrm{s}\right) \times 6$ hrs $\times 3600 \mathrm{~s} \times 0.02 \mathrm{~kg}]$

Table 1 shows the mean depth, width, speed and volume of water flow per second for different streams used in the current trial. Stock solution of endod was made by dissolving 10-15 kg of endod powder in 80-120 liter of water. It was then stirred occasionally for $16 \mathrm{hrs}$ which was then reconstituted to $150-200$ liters. Endod solution was then applied to the streams continuously so that the water body is treated with $20 \mathrm{~g}$ of endod per $\mathrm{m}^{3}$ of water for $6 \mathrm{hrs}$.

Table 1. Particulars of the streams and the amount of endod applied

\begin{tabular}{lllllll}
\hline Stream & PA & $\begin{array}{l}\text { Mean } \\
\text { depth } \\
(\mathrm{m})\end{array}$ & $\begin{array}{l}\text { Mean } \\
\text { width } \\
(\mathrm{m})\end{array}$ & $\begin{array}{l}\text { Mean } \\
\text { speed } \\
(\mathrm{m} / \mathrm{s})\end{array}$ & $\begin{array}{l}\text { Volume of water } \\
\text { flow } \\
(\mathrm{m} 3 / \mathrm{s})\end{array}$ & $\begin{array}{l}\text { Endod applied } \\
\text { for 6 hrs } \\
(\mathrm{Kg})\end{array}$ \\
\hline Degoye & Lalige & 0.15 & 0.23 & 0.83 & 0.03 & 12.96 \\
Sim Aytere & Amawute Gifitige & 0.13 & 1.91 & 0.25 & 0.063 & 27.22 \\
Aleltu & Betet wenz & 0.2 & 1.02 & 0.18 & 0.04 & 15.86 \\
Reji & Amawute Gifitige & 0.2 & 1.15 & 0.18 & 0.041 & 17.7 \\
Fulle & Betet wenz & 0.14 & 1.66 & 0.31 & 0.072 & 31.1 \\
$\begin{array}{l}\text { Aleltu } \\
\text { Genetemariam }\end{array}$ & Genetemariam & 0.54 & 1.91 & 0.06 & 0.062 & 26.78 \\
\hline
\end{tabular}

Estimation of leech prevalence

Estimation of prevalence of leech was assessed 4 times; before application, 24 hrs, 10 days and 30 days post application of endod. This was done by assigning 5 people at a time to collect leeches with in 50 meters distance along the stream at each specific site for five minutes and number of leeches collected per person per 5 minutes was recorded. The average number of leeches counted per person from each site of the stream was then used to determine the prevalence of leach in each stream.

Effect of endod on other non-target aquatic fauna

Different fresh water aquatic animals were scooped before and one day after application of endod. Samples of these animals were preserved in $70 \%$ ethanol. The aquatic animals were identified based on key anatomical structures. The effect of endod on these animals was assessed based on qualitative abundance 
of the animals before and after application of endod and searching for dead aquatic animal species 1 day post-application of endod along the stream.

Statistical analysis

Mean number of leeches counted per person per five minutes was calculated by simple arithmetic mean and percentage reduction post application was done by subtracting mean number of leech before treatment from mean number after treatment divided by mean number before treatment and multiplying by 100.

\section{Results}

Interview made with livestock owners and communities in the study area indicated that the leech problem is getting serious and is affecting both cattle and humans. Of the 20 randomly interviewed people, $95 \%$ of the respondents considered leech as the major animal health problem in the district. All respondents express that leech commonly infect cattle in the area while $20 \%$ of them also occasionally see equine, especially horse infected by leech. The farmers around Aleltu Genetemariam stream mentioned that several cattle mainly of immature age died of leech infestation. About 50 calves that were watered at this particular stream died during the last 5 years due to leech infestation. According to these informants, some farmers near the stream have already abandoned keeping cattle due to leech infestation. Some animals were infested with large number of leeches as high as 16 leeches at a time. There is also occasional attack of humans while drinking water from streams contaminated with leech especially in children. Sixty-five percent of the respondents have seen human infected by leech at least once in their life. Focused group discussion among farmers in the study area revealed that leech infestation in the area was occasional, but its impact is increasing during the last few years. In the past, leech problem was observed only during the late dry season mainly from January - March. However, now a day, leech infestation starts at early dry season (November) and continues until May.

All streams examined were infested by leech before application of endod and mean number of leech count per person per 5 minutes ranged from 16.8 to 38 (Table 2). In November 2009 random examination of 10 cattle from a herd of 25 by thorough inspection of oro-pharyngeal region showed that $4(40 \%)$ of them were infested by leech. 
Table 2. Abundance of leeches in different streams based on the average number of leeches counted per person per 5 minutes before application of endod

\begin{tabular}{lll}
\hline Stream & Kebele & $\begin{array}{l}\text { Mean no of leech count/per- } \\
\text { son/5 minutes }\end{array}$ \\
\hline Degoye river & Lalige & 38 \\
Sim Aytere & Amawute Gifitige & 31.6 \\
Aleltu & Betet wenz & 19.2 \\
Reji & Amawute gifitige & 16.8 \\
Fulle & Betet wenz & 25.4 \\
Aleltu Genetemariam & Genetemariam & 22.4 \\
\hline
\end{tabular}

Based on the interview, 1 month after treatment of stream with endod, most of the respondents indicated a dramatic reduction in leech infestation of their cattle. They also witnessed that the number of leeches in the treated stream was very minimal, they saw only rarely. Random oro-pharyngeal examination of 10 cattle (herd of 25) was made one month after application of endod and none of them were found infested by the parasite.

Application of endod resulted in mortality of most of the leech population in the streams. Mortality of leeches was observed as of 2 hrs following application. Soon after application, the leeches become restless and highly motile before death. The reduction in percentage of leeches was monitored for 1 month. Only few largely engorged leeches, which probably were dropped from cattle during post application of endod, were detected in the streams. Percentage reduction of number of leeches in the streams at different days post application of endod is shown in Table 3.

In addition to leech, other aquatic fauna such as tadpoles, adult frogs and different round worms were affected by the application of endod. Mortality of tadpoles was evident few hrs after application; and 24 hrs post application, a number of dead tadpoles was noticed along the streams. However, 30 days post application of endod; there were large number of tadpoles in each treated water bodies. On the other hand different water insects such as water bugs, Notonotcidae and Corixa species were not affected by application of endod at the dose used for leech control. 
Table 3. Efficacy of endod on leeches in the different streams.

\begin{tabular}{lcccc}
\hline Stream & \multicolumn{3}{c}{ Mean leech count/ person / 5 minutes(\%reduction) } \\
\cline { 2 - 5 } & 38 & $\begin{array}{c}\text { Day 1 post ap- } \\
\text { plication }\end{array}$ & $\begin{array}{c}\text { Day 15 post } \\
\text { application }\end{array}$ & $\begin{array}{c}\text { Day 30 post } \\
\text { application }\end{array}$ \\
\hline Degoye river & 31.6 & $0(100)$ & $1(97.37)$ & $0.17(99.55)$ \\
Sim Aytere & 19.2 & $0(100)$ & $0.17(99.9)$ & $0.33(99.46)$ \\
Aleltu & 16.8 & $0(100)$ & $0.33(98.28)$ & $0(100)$ \\
Reji & 25.4 & $0(100)$ & $0.5(97.02)$ & $4.2(75)$ \\
Fulle & 22.4 & $0(100)$ & $0(100)$ & $0(100)$ \\
Aleltu Genetemariam & & $0(100)$ & $0(100)$ & $1.17(94.78)$ \\
\hline
\end{tabular}

Three months post application of endod, the community was again interviewed on the level of reduction in problem of leech due to endod application, and all of them agreed that endod application dramatically decreased the leech population in the streams and animal infestation was rarely encountered. Fifty percent of the respondents agreed that they did not see their animals infested by leech for 3 months post application of endod, $25 \%$ of the respondents reported that their animals were protected for 2 months while the remaining $25 \%$ reported application of endod protected their animals only for one month.

\section{Discussion}

The results of interview of local communities and initial field assessment show that leech is a serious livestock and human health problem in Sodo district. The probable reason for increased impact of leech infestation during the last few years could be due to rapid fall in the volume of water at early dry season leading to stagnancy and slow flow of water creating conducive environment for leech multiplication for the whole dry season of the year. According to the local communities, the size of streams have dramatically reduced to low level at early dry season (November) which was not the case until January during earlier years. Fast moving water bodies are not suitable for multiplication of leeches.

Application of endod on the streams at concentration of $20 \mathrm{~g} / \mathrm{m}^{3}$ of water for 6 hrs has shown magnificent reduction in prevalence of leech in water bodies as well as in cattle population of the area. Complete eradication of leeches was achieved within 24 hrs of application which persisted for 30 days in most of the streams. This finding is in agreement with the previous laboratory evaluation of endod on leech (Getachew Tilahun, et al., 2002). The current study revealed that endod could render water bodies free of leeches for a minimum of 30 days. The probable reason for low reduction in the population of leech 30 days post 
application of endod in Reji stream compared to other streams could be due to the fact that there was heavy rain and flood above the places where endod was applied leading to contamination of free area by leech from upstream.

Toxicity of endod to tadpoles is in agreement with the previous laboratory studies which recorded $90 \%$ mortality at concentration of 19 parts per million (ppm) (Aklilu Lemma et al., 1979). However, re-infestation of streams by tadpoles 30 days post application was observed. This could be due to the fact that endod is less effective against eggs of frogs at hirudincidal concentration. Absence of toxicity to various water insects at hirudinicidal concentration is also in agreement with earlier report by Aklilu Lemma et al (1979) in which most of them required higher concentration to induce $90 \%$ mortality.

The local communities were advised not to drink treated water bodies on the day of application both for human and animal consumption for safety purpose. However, there were some animals who drunk the water on that same day and no complaint of toxicity was reported. This indicates that endod doesn't cause serious toxicity to animals at concentration used to treat water bodies for leech control $\left(20 \mathrm{~g} / \mathrm{m}^{3}\right)$. The dose required for leech control however may vary depending on the type of water medium (Getachew Tilahun et al., 2002) and in cases where higher doses are required to treat water bodies; the issue of toxicity to non-target animals should be considered. A series of studies on the properties of this plant have shown that it has low toxicity to mammals, microflora and fauna and rapid biodegradability (Aklilu Lemma, 1984; Ekue, et al., 1984; Lambert, et al., 1991; Maria and Aklilu Lemma; Per Molgaard et al., 2000).

In general, the current study demonstrated that endod can be used to control leech at low concentration without causing serious effect on most of the aquatic fauna as well as humans and livestock. However, care should be taken in using appropriate concentration and in water bodies that contain fish as previous studies have shown that endod is toxic to fish at similar concentration required to kill leeches.

\section{Acknowledgements}

We are highly grateful for the staff of Sodo District Office of Agriculture and Rural Development, district administrative staff, as well as local communities for unreserved cooperation during the field work. We are also indebted to Mr. Lidetu Tariku for his continuous assistance in facilitating cooperation of local communities during field visits to the study area. 


\section{References}

Cherinet, T., 2000. Preliminary studies towards strategic control of parasitic leeches using traditional plants in north western part of the Amhara Region of Ethiopia, Technical research report, Ethiopian Science and Technology Commission pp. 41

Edward, B., 1998. Black's Veterinary Dictionary, JAYPEE brothers, Medical Publishers, New Delhi, India

Ekue, J.M. Mamo, E. and Blumenthal, U., 1984. Toxicology of Endod, Report of Working Group I, Phytolacca dodecandra (Endod), Tyccoly Int. Pub.Ltd. London PP. 65-71.

George, J. K. and Georgi, M.E., 1990. Parasitology for Veterinarians $5^{\text {th }}$ edition. W.B.Saunders Company, Philadelphia, USA.

Lambert, J.D.H., Temmink, J.H.M., Marquis, J., Parkhurst, R.M., Lugt, C.B.,Lemmich, E., Yohannes, W.L. and De Savigny, D., 1991. Endod: Safety evaluation of a plant molluscicide. Regul.Toxico.Pharma. 14, 189-201.

Lapage, G., 1962. Monnig's Veterinary Hematology and Entomology $5^{\text {th }}$ editon. Bailliere, Tindall and Cox Ltd. London, UK.

Lemma, A., 1970. Laboratory and field Evaluation of the molluscicidal properties of Endod (Phytolacca dodecandra), Bull. WHO 42, 597-612.

Lemma, A., 1984. Another development in schistosomiasis: The case of Endod for use as Molluscicide: Back ground and Historical review, Phytolacca dodecandra (Endod), Tyccoly Int. Pub. Ltd, Dublin, Ireland.

Lemma, A., Heyneman, D. and Kloos, H., 1979. Studies on molluscicidal and other properties of the endod plant Phytolaca dodecandra, Institute of Pathobiology, Addis Ababa University, Addis Ababa, Ethiopia, pp.522.

Maria, G. and Lemma, A., 1984. Comparative toxicology studies of three molluscicides (Baylucide,Frescon and Endod) to Microflora and fauna,Fish,Crustacea,Aquatic insects and other arthropods, Phytolacca dodecandra(Endod), Tyccoly Int. Pub. Ltd. London, UK.

MOA. 2006. Extension package on control of leech using endod, Ministry of Agriculture, Sept. 2006, Addis Ababa, Ethiopia. 
Per Molgaard, Alex, C., Else, L., Petr, F., Chalotte, W., Flemming, I. and Bent, H., 2000. Biodegradability of molluscicidal saponins of Phytolacca dodecandra, Regul. Toxico. Pharma. 32, 248-255.

Schmidt, G. D., 1994. Essentials of Parasitology, Universal Bookstall, New Delhi, $6^{\text {th }}$ Edition.

Soulsby, E, J, L., 1986. Helminths, Arthropods and Protozoa of domesticated animals, $8^{\text {th }}$ edition, Bailliere Tindall, London, UK.

Tarekegne, M., 2006. Leech control using Endod at Mullo-Sululta district of North Oromia, a paper presented on the workshop on Leech control using Endod, held at Sheraton Addis, Addis Ababa, April 3, 2006.

Tilahun, G., Eguale, T., and Kassa T., 2003. Effect of Endod on parasitic leech, Lymnatis nilotica, Bull. Anim. Helth. Prod. 51, 75-81.

Tsegaw, A. 2006. Leech control using Endod at North Gonder of Amhara region, a paper presented on the workshop on Leech control using Endod, held at Sheraton Addis, Addis Ababa, April 3, 2006 